\title{
Humanitarismo, guerra e innovación tecnológica: el caso de Cruz Roja Española
}

\section{Humanitarianism, war and technological innovation: the case of the Spanish Red Cross}

$\mathrm{L}$ as actividades y debates en que se vio envuelto el movimiento internacional de Cruz Roja, desde su bienio fundacional (1863-1864), ofrecen un valioso observatorio para explorar los procesos de producción y circulación de innovaciones tecnológicas destinadas a paliar el sufrimiento de las víctimas en guerras y otras situaciones catastróficas. Valga precisar que por "innovación tecnológica" de carácter humanitario, en el ámbito de la medicina de guerra, entendemos no solo los nuevos instrumentos y equipamientos médicos, sino también las medidas innovadoras en la logística médico-militar y en los procedimientos de movilización de la solidaridad hacia las víctimas de la guerra entre la ciudadanía; todo ello en consonancia con un esquema taxonómico desarrollado por Habermas (1987-1988, 1989) y Foucault (1990), que obviamente confiere al término "tecnología" una acepción muy amplia.

Inicialmente el "Comité de Ginebra" (luego conocido como Comité Internacional de Cruz Roja, CICR) tan solo contemplaba la asistencia bajo el amparo de la Convención de Ginebra (1864) de soldados enfermos y heridos en guerras internacionales. Este marco jurídico se vio pronto desbordado por nuevas demandas de actuación humanitaria a que las sociedades nacionales de Cruz Roja se veían compelidas por la proliferación, tanto de conflictos violentos de otro orden (guerras civiles y coloniales, movimientos insurreccionales) como de otros desastres (epidemias, inundaciones, terremotos, sequías, hambrunas y accidentes mineros o de transporte) o circunstancias carenciales relativas a la asistencia sanitaria y salud pública que afectaban al conjunto de la sociedad civil.

La historia de Cruz Roja Española (CRE) brinda un expresivo ejemplo de en qué medida nuevas demandas humanitarias movieron a distintas sociedades nacionales de la "Asociación Internacional de Socorro a los Soldados Heridos en Campaña" a extender sus intervenciones conforme a los valores consagrados por la primera Convención de Ginebra más allá de los límites jurídicos de esta. En efecto, los debates y actividades en que se vio envuelta la CRE desde sus inicios, en 1863, hasta el final del conflicto rifeño (1927) brindan un magnífico observatorio para explorar los procesos de producción y circulación de innovaciones tecnológicas destinadas a paliar el sufrimiento de las víctimas en conflictos civiles y coloniales, así como su uso extensivo en problemas de salud de la población civil. 
Este dossier se inserta en el marco del proyecto de investigación "Sanidad militar, medicina de guerra y humanitarismo en la España del siglo XIX" (HAR2011-24134), financiado por la Dirección General de Investigación (Gobierno de España). Tres de los cuatro artículos integrantes del dossier abordan sendos estudios de caso relativos a distintas cuestiones y periodos de la historia de CRE; el cuarto reproduce, debidamente presentado, un documento inédito asociado al primer estudio de caso. Este se centra en los primeros años del movimiento internacional de Cruz Roja y presta atención al modo cómo este movimiento propició la confluencia en una red científica internacional, de un amplio grupo de médicos preocupados por la ayuda humanitaria en la guerra. Esta red experta potenció el conocimiento e intercambio de innovaciones tecnológicas destinadas a humanizar la guerra y su introducción en distintos países a la vez que contribuyó a la consolidación del papel de Cruz Roja en la esfera internacional. Si el número y variedad de innovaciones tecnológicas que CRE incorporó durante la última guerra carlista (1872-1876) permiten estimar la rapidez con que se coprodujo este cuerpo de conocimientos y prácticas, el informe de Nicasio Landa, proponiendo un nuevo sistema de suspensión elástica de camillas para el traslado de heridos, ilustra de modo bien expresivo la materialización de este proceso de coproducción a escala local.

Los otros dos estudios de caso abordan la acción de CRE en conflictos derivados del colonialismo español. El primero de ellos examina su atención en territorio metropolitano a los soldados heridos y enfermos repatriados de las últimas guerras coloniales de ultramar (Cuba, 1895-1898 y Filipinas, 1896-1898) y de la Guerra del Rif (1921-1927). Tal como se muestra, tras organizar las labores de acogida en hospitales provisionales permanentes destinados a los militares enfermos, heridos y mutilados, llegados de ultramar en los últimos años del siglo XIX, durante las primeras décadas del siglo XX, CRE no solo prosiguió su tradicional atención a nuevas demandas surgidas en el ámbito militar, como las derivadas de la Guerra del Rif, sino que, de modo similar a otras sociedades nacionales de Cruz Roja, extendió su acción al ámbito civil, respondiendo a carencias asistenciales y de salud pública con acciones de divulgación sanitaria, de lucha contra enfermedades epidémicas (sobre todo contra la gripe de 1918-1919 y la poliomielitis a partir de 1929), y de atención sanitaria a personas carentes de recursos.

El estudio de caso que cierra el dossier defiende, a partir del análisis de la actuación de CRE en Marruecos durante las dos últimas décadas del siglo XIX y tres primeras del XX, la función central que los Estados-nación continuaron desempeñando en la organización y actividades del movimiento de Cruz Roja tras la Primera Guerra Mundial. En efecto, la secular inestabilidad de España como Estado - agravada por el desastre colonial de 1898 que terminó primero con el proyecto regeneracionista de crear una Cruz Roja marroquí a finales del siglo XIX - se tradujo, tras la división colonial de Marruecos en 1912, en el progresivo arrinconamiento de CRE por la competencia de la Cruz Roja francesa, la internacionalización de Tánger y un rechazo local que culminaría en la llamada Guerra del Rif de 1921-1927, cruento conflicto a medio camino entre revuelta anticolonial y guerra internacional.

Jon Arrizabalaga

Institución Milà i Fontanals/Consejo Superior de Investigaciones Científicas 


\section{REFERENCIAS}

FOUCAULT, Michel.

Tecnologías del yo y otros textos afines. Barcelona: Paidós; ICE-UAB. 1990.

HABERMAS, Jürgen.

El discurso filosófico de la modernidad. Madrid: Taurus. 1989.
HABERMAS, Jürgen.

Teoría de la acción comunicativa. Madrid: Taurus. 2v. 1987-1988.

\section{$\rightarrow \rightarrow \rightarrow<<<$}

